\title{
Resistance as madness in The Catcher in the Rye
}

\begin{abstract}
J. D. Salinger's The Catcher in the Rye (1951) is a story of Holden Caulfield's crises with his society. Holden is a teenager who has a lingering position between accepting and rejecting the cultural codes of his decade. In this paper, we intend to analyze Holden's resistant character based on Foucauldian concepts of madness, power and resistance. Heading this aim, we explain how society eliminates the resistant individuals in Foucauldian views. Through close reading of the text, we intend to find a relationship between madness, power and resistance. We also hypothesize that in this context Holden's resistance to disciplinary power is regarded as madness. Moreover, we hypothesize that Holden like a sociologist figure scrutinizes his society to figure out society's madness by following the cultural codes. However, because of his individuality and resistance, he is considered mad and eventually is sent to a sanitarium to be cured. Furthermore, we observe that Salinger challenges society's cultural codes through Holden's crises and presents a new form of resistance to social norms in his novel.
\end{abstract}

Keyword: Madness; Resistance; Disciplinary system; Power; Cultural codes 